\title{
Contextualism and Knowledge Norms
}

\author{
Alex Worsnip
}

To appear in Jonathan Ichikawa (ed.), The Routledge Handbook of Epistemic Contextualism

Recent epistemology has seen a turn toward understanding the norms governing various practices in terms of knowledge. ${ }^{1}$ Strikingly, such norms have been claimed as a data point both in favor of and against epistemic contextualism. In this chapter, we investigate the relationship of the two through a critical survey of the literature.

\section{Knowledge norms introduced}

"Knowledge norms", in the sense at work in this chapter, are norms that claim that knowledge is necessary and/or sufficient for something's being appropriate. Slightly more specifically, they tend to be claims that knowledge of a proposition $\mathrm{p}$ is necessary and/or sufficient for its being appropriate to do something related to $\mathrm{p}$ : for example, to assert $\mathrm{p}$, to act on $\mathrm{p}$, to employ $\mathrm{p}$ as a premise in one's reasoning, or even to believe p. Let us work with an example, the knowledge norm of assertion:

KNA. S (epistemically) may assert $\mathrm{p}$ if and only if one knows $\mathrm{p}$.

Some observations. First, because I have stated KNA as a biconditional, it commits one to both the sufficiency and the necessity of knowledge for permissible assertion. However, one might only want to endorse one of these two distinct claims. Such "one-direction" claims are still, in my sense, fullblooded knowledge norms. I am working with the biconditional simply to fix ideas.

Secondly, KNA uses the permissive modal 'may', rather than the requiring modal 'ought'. This, I take it, is orthodox. Most theorists would not want to endorse the (universally quantified) claim that if one knows $\mathrm{p}$, one ought to assert $\mathrm{p}$, even in some peculiarly epistemic sense of 'ought'. For surely it is at least sometimes permissible (in every sense) to remain silent about what you know. So as long as we hold on the sufficiency direction of KNA, we will not want to use 'ought' to state it. However, assuming that 'ought $\Phi$ ' entails 'may $\Phi$ ', as it does on the orthodox semantics and logic for modals, KNA as stated already entails the claim that knowing $\mathrm{p}$ is necessary for it to be the case that one ought to assert p. ${ }^{2}$

Thirdly, note the qualifier 'epistemically' on 'may'. This is something of a term of art. The idea is that if S epistemically may assert $\mathrm{p}$, there is nothing about S's epistemic position that makes it impermissible to assert $\mathrm{p}$. Uncontroversially, there may be something non-epistemic that makes it impermissible for $\mathrm{S}$ to assert $\mathrm{p}$, even when $\mathrm{S}$ knows $\mathrm{p}$. For example, perhaps asserting $\mathrm{p}$ would be very

\footnotetext{
${ }^{1}$ See e.g. Williamson (2000: esp. ch. 11; 2005); DeRose (2002); Hawthorne (2004); Hawthorne \& Stanley (2008); Fantl \& McGrath (2009); Benton (2011); Turri (2011); Blaauw (2012).

2 Slightly more strongly, it also entails a wide-scoped version of the necessity-claim using 'ought': one ought to (assert $\mathrm{p}$ only if one knows p). This is Williamson's (2000: 243) formulation.
} 
hurtful to the listener, or betray a secret upon which someone's life depends. ${ }^{3}$ Then asserting $\mathrm{p}$ is not morally permissible, but may still be epistemically permissible in our sense. These senses of 'may' are not obviously incommensurable: perhaps for asserting $\mathrm{p}$ to be permissible simpliciter, it must be permissible (at least) both epistemically and morally. But we can nevertheless use 'may' in a way that brackets non-epistemic factors and focuses only on epistemic permissibility. Note that this usage of 'may' is still a normative usage, rather than the purely expectational usage that is at work in sentences like "the train may be late" on their most natural readings - a usage that is, confusingly, also often called the "epistemic" sense of 'may'.

Fourthly, it is sometimes claimed that KNA is constitutive of assertion. The claim here is that part of what it is for something to be an assertion is that it be subject to KNA. This claim is ancillary to KNA itself. The point here is delicate. If KNA is a necessary truth, then nothing can be an assertion without being subject to KNA. However, plausibly there is more to constitutivity than this. Compare:

Reading-No Enslavement. One may read a book only if reading the book does not lead to the enslavement and torture of the rest of humanity.

This claim seems true, and necessarily so, so nothing could be an act of reading a book unless it were subject to this norm. But it is not plausible that it is constitutive of the act of reading a book - part of what it is to read a book - that such an act is subject to Reading-No Enslavement. One thing that makes this clear is that one can specify what it is to read a book without any reference to Reading-No Enslavement. Moreover, there is no sense in which the act of reading a book involves "representing oneself' as staying away from enslavement and torture. Conversely, perhaps there is no way of telling whether something is an assertion (rather than some other speech act) that does not make reference to KNA - to the conditions under which the act is epistemically permissible. Perhaps all assertions "represent themselves" as satisfying KNA by being known. ${ }^{4}$ If this were right, it might suggest that it is part of the very essence of assertion that it is governed by KNA, in a way that it is not part of the very essence of book-reading that it is subject to Reading-No Enslavement. But, as Reading-No Enslavement shows by analogy, this will not follow merely from KNA itself.

Briefly, without any claim to comprehensiveness, let's survey some of the data offered in favor of knowledge norms. The most fundamental kind of data that has been offered in favor of knowledge norms concerns the ways in which we naturally assess the relevant practices - assertion, action, reasoning - in terms of what a subject knows or knew. Consider, for example:

\footnotetext{
${ }^{3}$ A complication: what one is permitted to assert or rely on, even in the sense we are interested in here, can sometimes depend on "pragmatic" or "non-epistemic" factors, such as what is at stake (see section $3 b$ below). This may seem to collapse the distinction between epistemic and non-epistemic permissibility. However, going carefully, the distinction can remain intact. The claim is that when the stakes go up, the epistemic standards that one must meet in order to permissibly assert $\mathrm{p}$ become more stringent. So the idea is that practical factors can influence what is epistemically permissible. Asserting p might then become epistemically impermissible, because one's epistemic position is not strong enough to meet the new epistemic standards. This is still distinct from (im)permissibility that is non-epistemic in the sense that I am bracketing. In this latter sense, asserting p might be, for example, impermissible because asserting p will be rude or hurtful. This does not just make it the case that one has to be in a really strong epistemic position to assert p: rather, it makes it impermissible to assert $\mathrm{p}$, no matter how strong one's epistemic position.

${ }^{4}$ Indeed, the idea that to assert $\mathrm{p}$ is to "represent" oneself as knowing p predates the explicit idea that knowledge is the norm of assertion. See e.g. Unger (1975: ch. 6); Slote (1979).
} 
(1) You shouldn't have let my daughter play with your dog! For all you knew, it might have bitten her! $!^{5}$

Note that here it isn't sufficient to excuse the act that the dog didn't in fact bite the daughter; the agent is still criticizable on the grounds that she didn't know that it wouldn't do so. ${ }^{6}$ By contrast, the agent can defend herself like so:

(2) I knew that my dog wouldn't bite your daughter, since I know it has no teeth. So I didn't do anything wrong.

There are also certain "clashing" sentences where this clash may be well-explained by knowledge norms:

(3) \#I know that the ice will hold my weight, but I shouldn't cross in case it doesn't hold my weight. $^{7}$

If knowing $\mathrm{p}$ is sufficient for relying on $\mathrm{p}$ in action, the oddness of (3) has an explanation.

In the case of assertion, some have claimed that knowledge norms explain the "clashes" of some utterances, in this case some famous "Moore-paradoxical" utterances: ${ }^{8}$

(4) \#It's raining, but I don't know it's raining

This sentence's badness can be explained if knowledge is necessary for permissible assertion. For if one is only warranted in asserting the first conjunct if the second conjunct is false, no wonder the sentence sounds odd.

Interestingly, the badness of (3) and (4) support the sufficiency of knowledge for relying on $\mathrm{p}$ in action, and the necessity for knowledge for asserting p, respectively. One might expect there to be analogous sentences for the inverse cases (necessity for action and sufficiency for assertion), but those are harder to construct. It often at least not apparently incoherent to say that one is relying on something that one doesn't know. And the clash between saying one knows $\mathrm{p}$ and refusing to assert p can be explained without a knowledge norm: since 'knows' is factive, why would one be willing assert that one knows $\mathrm{p}$ but not be willing to assert $\mathrm{p}$ ? So the data in favor of knowledge-norms is complex. It may more strongly support sufficiency-norms for some practices (action) but more strongly support necessity-norms for other practices (assertion). And of course, it is open to theorists to accept knowledge norms about some practices but not others. ${ }^{9}$

5 The example is based on one given by Hawthorne \& Stanley (2008: 572).

${ }^{6}$ Ibid.

7 The example is based on one given by Fantl \& McGrath (2009: 73-4; 82).

${ }^{8}$ See e.g. Williamson (2000: 253); DeRose (2009: 96-7).

${ }^{9}$ For discussion of some discontinuities between assertion and practical reasoning that may drive apart the norms for the two, see Brown (2012) and Worsnip (2015b: esp. 321). Some such discontinuities are especially pointed for 


\section{The need for contextualists to "relativize" knowledge norms}

As anyone reading this volume should know by now, contextualism is a semantic thesis about the word 'know(s)', according to which the semantic value of this term varies across conversational contexts. In some contexts, 'knows' expresses a concept that one must meet very demanding standards to satisfy; in other contexts, it expresses a concept that one must meet less demanding standards to satisfy. Moreover, on standard contextualist views, there can be true utterances both of 'S knows p' and of 'S doesn't know p', even holding fixed the same subject S, proposition $p$, and S's circumstances (evidence, practical situation, etc) with respect to $\mathrm{p}$. This will be so when $\mathrm{S}$ does meet the standards for knowing associated with the use of 'know' in lower-standards contexts, but fails to meet the standards for knowing associated with the use of 'know' in higher-standards contexts. As some contextualists have put the point, the subject knows ${ }_{\mathrm{LO}}$ but doesn't know ${ }_{\mathrm{HI}}$, or has "low-grade knowledge" but not "high-grade knowledge".

But it now becomes clear that, for a contextualist, it is radically indeterminate what KNA (understood as a sentence) says. What "grade" of knowledge is it that KNA says is required for permissible assertion? KNA itself is an implicitly universally quantified sentence stated in the course of abstract theorizing, so it's hard to say which semantic value of 'knows' the context in which KNA is uttered would determine.

Clearly, the contextualist cannot say that KNA is true on every value of 'knows', so that it holds in metasemantic generality. For this leads to contradictions. Since one can have low-grade knowledge while lacking high-grade knowledge, it cannot be that low-grade knowledge is sufficient for permissible assertion, but that high-grade knowledge is necessary for permissible assertion. ${ }^{10}$

A contextualist might next try specifying a single value of 'knows' that is the one picked out by 'knows' as it occurs in KNA. But which one? Given the diversity of potential semantic values for 'knows', it feels arbitrary to pick one privileged value of 'knows' that plays the crucial role of being necessary (and perhaps sufficient) for assertion; it is not even clear how one would go about specifying such a value. And once one says that one semantic value of 'knows' is privileged in this way, it seems that there will be pressure to say that this is the "core" or "real" sense of 'knows' in a way that undercuts contextualists' pluralism about the range of concepts that 'knows' can express.

contextualists. Suppose that the mentioning of error-possibilities with respect to p sometimes raises those errorpossibilities to salience, such that one no longer 'knows' $\mathrm{p}$ by the conversational standards. It's plausible that the mentioning of such error-possibilities can also affect whether it is permissible to assert $\mathrm{p}$. But is it really plausible that the mentioning of error-possibilities can make a difference to whether it is permissible to rely on p in one's reasoning? Such a verdict would be at radical odds with standard decision-theoretic pictures of rational action.

${ }^{10}$ It does not help to retreat to a one-direction version of KNA, according to which knowledge is necessary or sufficient for epistemically permissible assertion, but not both. If one holds that knowledge is only necessary for epistemically permissible assertion, the idea that KNA holds in metasemantic generality would entail that assertion is warranted only when one meets the most demanding possible standards for 'knows', which seems too strong to be necessary. If one holds that knowledge is only sufficient for epistemically permissible assertion, the idea that KNA holds in metasemantic generality would entail that assertion is warranted whenever one meets the least demanding possible standards for 'knows', which seems too weak to be sufficient. 
So the most promising route is for the contextualist to instead modify KNA (and other knowledge norms), so that it is, as Keith DeRose calls it, "relativized" to a conversational context: ${ }^{11}$

KNA-Relativized. S (epistemically) may assert $\mathrm{p}$ if and only if, in S's conversational context, the utterance 'I know p' would be true.

KNA-Relativized moves the right-hand side of KNA up one semantic "level". Although S is the subject here, that subject herself inhabits a particular conversational context, and is capable of selfattributing knowledge. The natural idea behind KNA-Relativized is that it is the subject's own conversational context, and the resulting value of 'know', that is relevant when it comes to assessing the normative appropriateness of the subject's utterances. However, it is important to see that KNARelativized does not collapse the normative appropriateness of asserting $\mathrm{p}$ with the normative appropriateness of asserting that one knows $\mathrm{p} .{ }^{12}$ The idea is that asserting $\mathrm{p}$ is appropriate only if a self-attribution of knowledge would be true, not that it is appropriate only if a self-attribution of knowledge would itself be appropriate. It is part of the original idea behind KNA that some utterances are true but inappropriate. So KNA-Relativized leaves open the possibility that sometimes, one may assert $\mathrm{p}$ but may not assert that one knows $\mathrm{p}$.

\section{Knowledge norms and the contextualism-invariantism wars}

Let's assume for the sake of argument that we want to accept some kind of knowledge norms, and ask whether this favors or hurts contextualism in the debate between contextualists and invariantists. Since we've already seen that contextualists should accept relativized versions of knowledge norms if they want to accept knowledge norms at all, it will be an important part of this task to consider whether there is any reason to prefer unrelativized norms over their relativized equivalents (or vice versa). We will consider, in turn, an argument against contextualism from knowledge norms (due to John Hawthorne) and an argument for contextualism from knowledge norms (due to Keith DeRose).

\section{(a) Hawthorne's argument from knowledge norms against contextualism}

Hawthorne (2004: 85-91) offers what is effectively an argument for preferring unrelativized knowledge norms to their relativized analogues. Hawthorne's case turns on exploiting potential differences between the context of someone ascribing knowledge and the context of the subject of their knowledge-attribution. Suppose that a subject $S$ is in a low-standards conversational context but the ascriber is in a high-standards conversational context. And suppose that the subject's epistemic position with respect to some proposition $\mathrm{p}$ is such that, given these contexts, 'I know p' is true in the subject's mouth but 'S knows p' is false in the ascriber's mouth. By KNA-Relativized and the fact that 'I know p' is true in the subject's mouth, S (epistemically) may assert p. But then, since 'S knows p' is false in the ascriber's mouth, it should be true for the ascriber to say:

11 DeRose (2009: 99, 258-9). See also Hawthorne (2004: 88-9).

12 See DeRose (2009: 103-4) for an argument against such a collapse. 
(5) S does not know $\mathrm{p}$, but $\mathrm{S}$ may assert $\mathrm{p}$.

Likewise, suppose that the subject is in a high-standards context but the ascriber is in a low-standards context. Then, 'I know p' is false in the subject's mouth and so, by KNA-Relativized, S (epistemically) may not assert $\mathrm{p}$. But, since, 'S knows $\mathrm{p}$ ' is true in the ascriber's mouth, it should also be true for the ascriber to say:

(6) S knows $\mathrm{p}$, but S may not assert $\mathrm{p}$.

According to Hawthorne, claims of the form of (5) and (6) sound odd; moreover, they clash with the fundamental idea that knowledge-attributions can be used to third-personally evaluate the propriety of assertions. But on the face of it, KNA-Relativized, together with contextualism about 'knows', commits us to the possibility that claims of the form of (5) and (6) can be true. By contrast, the unrelativized version of KNA seems to preclude the truth of (5) and (6). So, the unrelativized version of KNA does a better job of accounting for the intuitive role that knowledge-attributions play in the third-person evaluations of assertions. ${ }^{13}$ Since the contextualist can only accept KNA-Relativized, and not KNA, this ultimately constitutes an objection to contextualism itself. Analogous arguments can be made for other knowledge norms.

How might a contextualist reply to this? There are two potential strategies: one that involves modifying KNA-Relativized, and one that involves arguing that KNA-Relativized does not really have the bad consequences that Hawthorne claims it has. Let's begin with the first strategy.

As we observed earlier, in relativizing KNA, the contextualist shifted the right hand side of KNA up one semantic level, mentioning rather than using 'knows'. But the left hand side of KNARelativized continues to use rather than mention the normative term ('may') that is used to evaluate assertions. But what if we also shifted the left hand side of KNA up one level, to mention rather than use 'may'? Then, we would get:

KNA-Doubly-Relativized. An utterance of ' $\mathrm{S}$ (epistemically) may assert $\mathrm{p}$ ' in a context $\mathrm{C}$ is true if and only if the utterance ' $\mathrm{S}$ knows $\mathrm{p}$ ' in context $\mathrm{C}$ is true. ${ }^{14}$

By relativizing both sides of the biconditional, KNA-Doubly-Relativized brings third-person evaluations of the permissibility of assertions and third-person knowledge attributions back together.

\footnotetext{
13 Both Hawthorne (2004: 89) and Fantl \& McGrath (2009: 51) also make the simpler argument that unrelativized norms account for the intuitive ties between knowledge and assertion/action better than their relativized analogues, because they are simpler and because they link knowledge to assertion and action, rather than linking 'knowledge' to assertion and action. I think this is not decisive. The fundamental intuitive data we are trying to account for are those involving our tendency to assess assertions and actions in terms of knowledge - not an abstract theoretical claim about the relationship of knowledge to assertion and action. If the contextualist can show that a relativized principle accounts for that data equally well, I do not see why the unrelativized principle should be strongly preferred.

${ }^{14}$ Cf. DeRose (2009: 260), though DeRose neither accepts this principle nor offers it as a way of dealing with Hawthorne's objections.
} 
We are then back in a position where utterances like (5) and (6) could never be true, assuming that there is no context-shift in the course of their utterance.

Since the contextualist thinks that the semantic value of 'knows' can vary with the conversational context of the speaker, accepting KNA-Doubly-Relativized will commit her to also holding that the semantic value of 'may' can also vary with the conversational context of the speaker. Is this a problem? Hawthorne notes that "the relevant normative facts do not seem to be ascriberdependent" (Hawthorne 2004: 86), but construed as an objection to the present view, this rests upon a simple use-mention conflation. The present view is not that the normative facts depend on the context of the ascriber (whatever that would mean), but rather that the semantic value of a normative term ('may') - and hence potentially the truth-value of utterances that use it - depends on the context of the ascriber. Ironically, this conflation parallels exactly the mistake in many critiques of contextualism about 'knows' far less sophisticated than Hawthorne's, ${ }^{15}$ which falsely impute to contextualists the (borderline unintelligible) view that whether a subject knows $\mathrm{p}$ depends on the context of "the ascriber" (whoever that is, given that this view makes no reference to any ascription). As Hawthorne himself points out, contextualism about 'knows' is instead the view that the semantic value, and hence potentially the truth-value, of the utterance "S knows p", varies with the context of ascription. ${ }^{16}$

In and of itself, the idea that the semantic value of 'may' (and other deontic modals) varies with conversational context is hardly odd; in fact, it is semantic orthodoxy. ${ }^{17}$ Now, admittedly, the contextualist who accepts KNA-Doubly-Relativized is committed to something more specific than this. In particular, she is committed to allowing that the truth-value of utterances like "S may assert p" can depend in part on the standards for knowing $\mathrm{p}$ that are in play at the ascriber's, rather than the subject's, context. But I do not think this is obviously fatal. What unintuitiveness there may appear to be here can be further cushioned by a move that the contextualist makes in numerous other contexts: namely to insist that the standards that govern a conversational context are not mechanically determined by what is practically at stake for the speaker. ${ }^{18}$ Rather, often, the interests and practical situation of the subject can be salient (perhaps via their being salient to the speaker, and part of what she intends to talk with reference to). ${ }^{19}$ In contexts where she is talking about what the subject may assert or rely on, she will plausibly often be implicitly talking about what, from the subject's perspective, the subject may assert or rely on. In doing so, she may shift the contextually relevant value of 'knows'. KNA-Doubly-Relativized allows for this. It does not say that the contextually salient value of 'knows'

\footnotetext{
15 And which Hawthorne himself has been at pains to correct: see, e.g., Hawthorne (2005: 39).

${ }^{16}$ Ibid. See also DeRose (2009: 212-25).

${ }^{17}$ See, canonically, Kratzer (1981). For recent defenses and developments of this view see e.g. Björnsson \& Finlay (2010), Kratzer (2012), and Dowell (2013).

18 This point can be overlooked because of a slipperiness in usage of the word 'context', which can refer either to a context of conversation or to a practical situation (what the stakes are, etc). The contextualist can and should deny that the standards in play in a conversational context are always mechanically determined by the practical situation of the speaker. The practical situations of others who are not the speaker may often be conversationally salient, even to the speaker. While in a broad sense it is the standards of the speaker that matter, the speaker's standards can be influenced by the practical interests of others.

${ }^{19}$ See e.g. Greco (2008: esp. 424-5, 433-4); DeRose (2009: 246).
} 
must get fixed indepedently before determining the contextually salient value of 'may'; rather it allows for mutual influence between the two, as long as they always move along together.

For those who do not like KNA-Doubly-Relativized, let's explore the second strategy for resisting Hawthorne's argument. On this strategy, the contextualist hangs on to KNA-Relativized, but denies that it has the bad consequences that Hawthorne claims it does. This is the strategy pursued by DeRose (2009: ch. 7) in reply to Hawthorne. Again, we begin by recognizing that the practical situation of the speaker (construed narrowly as excluding indirect interest in or intention to discuss the practical situation of the subject) does not have a monopoly on determining the standards in play in the conversational context. Perhaps, when one talks about what the subject is warranted in relying on, one thereby tends to make salient standards for knowledge commensurate with what is practically at stake for the subject.

As DeRose notes, there is both a stronger and a weaker way of developing this view. On the stronger version, the claim is that in talking of what the subject is warranted in asserting or relying on, one automatically shifts the value of 'knows' to one determined by the subject's practical interests. On this view, (5) and (6) will come out false, since, in each sentence the second conjunct affects the semantic value of 'knows' as it occurs in the first conjunct, in such a way as to make the first conjunct come out false. KNA-Relativized, then, turns out not to automatically entail that sentences (5) and (6) can be true when asserted. The weaker version of the view has it that by talking about what the subject is warranted in asserting or relying on, the speaker at least creates the impression that corresponding standards for 'knows' are in play in the conversation. On this view, utterances (5) and (6) can be true, strictly speaking, but they will be infelicitous, because in each sentence, the second conjunct generates an implicature that is at odds with the first conjunct. Like Moorean conjunctions such as 'it's raining but I don't believe it's raining', they will be (potentially) true, but unassertable.

In sum, it is far from obvious that contextualists cannot deal with the sense that there is something wrong with utterances of the form of (5) and (6).

\section{(b) DeRose's argument from knowledge norms for contextualism}

DeRose also offers a positive argument for contextualism from knowledge norms ${ }^{20}$ It begins with the observation that what one is epistemically permitted to assert often depends upon one's practical circumstances and what is at stake. When it doesn't matter much to you (and your audience) whether $\mathrm{p}$, the epistemic standards for asserting $\mathrm{p}$ are lower than when it is extremely important whether $\mathrm{p}^{21}$

Here the relativized version of KNA, conjoined with contextualism about 'knows', can seem to have the upper hand. For contextualists can say that, generally, these high-stakes situations raise the standards that must be met for 'I know p' to be true in the speaker's mouth. So KNA-Relativized predicts that the standards for permissibly asserting $\mathrm{p}$ will go up, correspondingly. By contrast, a view where 'know' is semantically invariant, conjoined with the unrelativized version of KNA, may seem

\footnotetext{
${ }^{20}$ DeRose (2009: 98-102). See also Schaffer (2008).

${ }^{21}$ The kind of permissibility here is still epistemic because in this case, practical factors make it impermissible to assert $\mathrm{p}$ via raising the epistemic standards that one must meet to assert $\mathrm{p}$. This is distinct from the case where practical factors make it impermissible to assert p quite independently of what epistemic position one is in. See n. 3 above.
} 
to have difficulty making this prediction. If 'knows' always has the same semantic value, and whether one may assert $\mathrm{p}$ simply depends on whether one knows $\mathrm{p}$ in this single sense, it seems as though whether one epistemically may assert p cannot depend upon one's practical situation.

"Interest-relative" or "subject-sensitive" versions of invariantism avoid this problem by claiming that whether one knows $\mathrm{p}$ - even given a constant semantic value for 'knows' - can itself depend partly on one's practical situation and interests, such as how much it matters to one whether p. ${ }^{22}$ On this view, whether it is permissible to assert $\mathrm{p}$ can depend on the practical stakes because whether one actually knows $\mathrm{p}$ can depend on the practical stakes. ${ }^{23}$ However, DeRose also raises a related problem for interest-relative invariantism. ${ }^{24} \mathrm{~A}$ subject can be in a situation where a single proposition $\mathrm{p}$ is relevant to one's assertion, reasoning or actions in more than one way simultaneously. But maybe, with respect to one practical purpose, the stakes are low, but with respect to another practical purpose, the stakes are high. To give a slight variant on the concrete example that DeRose provides, suppose that Judith is simultaneously walking to the insurance office to purchase life insurance, and on the phone to a friend about her teaching plans for next year. With respect to the first purpose, it seems that Judith may not rely on the proposition that she will be alive next year. For if Judith could rely on this, Judith could reason to the decision not to purchase life insurance. But with respect to the second purpose, it seems that Judith may rely on the proposition that she will be alive next year, in outright asserting that she will be teaching philosophy of mind next year.

Now, DeRose points out that we are more likely to attribute knowledge that she will be alive next year to Judith if we are talking about her second purpose than if we are talking about the first. Contextualism accommodates this by saying that, depending on which purpose we are talking about, our standards will be different. Interest-relative invariantism, by contrast, doesn't seem able to mimic this explanation. Since she has both purposes simultaneously, interest-relative invariantists cannot vindicate both utterances attributing knowledge to Judith, and utterances attributing lack of knowledge to her.

I am not sure that this objection is decisive. Interest-relative invariantists, as the name suggests, posit that knowledge is (metaphysically) relative to interests. If it turns out that one can have different interests and purposes at a single time, it seems a relatively conservative extension of the view to explicitly relativize knowledge to different purposes, and say that Judith can know with respect to one purpose but not with respect to another. The interest-relative invariantist can then say that speakers are usually implicitly talking about whether Judith knows with respect to the purpose they are discussing. Admittedly, this concedes something to contextualism: sometimes 'Judith knows p' means 'Judith knows $\mathrm{p}$ relative to purpose $\mathrm{X}$ ', and sometimes it means 'Judith knows p relative to purpose Y'. But the contextualism conceded here is mild. Presumably all theorists already admit that knowledge-attributions are usually implicitly indexed to a time: 'Judith knows p', uttered at time t,

\footnotetext{
22 Even classical invariantists - invariantists who reject interest-relativism - have devised some interesting attempts to deal with the apparent stakes-sensitivity of warranted assertion and action. See e.g. Brown (2005); Williamson (2005); Nagel (2008).

23 See esp. Hawthorne (2004), Stanley (2005) and Weatherson (2011). See also Fantl \& McGrath (2009), though they leave open the possibility that both contextualism and interest-relativism are true. Chapter 19 of this volume takes up the contextualism/interest-relative invariantism debate.

${ }^{24}$ DeRose (2009: 269-76).
} 
usually (but not quite always) means 'Judith knows $\mathrm{p}$ at time t'. Since different utterances occur at different times, there is a very mild kind of contextualism at work here. Relativizing to a purpose simply allows for an analogous maneuver given the possibility of simultaneously knowing with respect to one purpose, but not with respect to another, at a single time. It does not posit systematic variability in the standards for 'knows' of the sort that full-blooded contextualists are committed to.

I conclude that, so far as we have seen, commitment to knowledge norms does not win the day either for contextualism or for invariantism. Of course, this issue remains open to further debate. But in what remains, I want to focus on a different possibility: that contextualism itself might motivate suspicion of knowledge norms.

\section{Reasons for contextualist suspicion of knowledge norms?}

As I mentioned earlier, contextualism about deontic modals like 'ought' and 'may' is relatively orthodox in semantics. It is also increasingly popular in metaethics. Many of the theoretical issues surrounding contextualism about 'knows' find analogues in the literature on modals. ${ }^{25}$ There is at least some pressure for contextualists about 'knows' to also be contextualists about modals.

This raises a question for proponents of knowledge norms. Knowledge norms say that assertion, action and other practices are to be normatively assessed in terms of the acting agent's knowledge. But according to contextualism about modals - at least "flexible" versions of contextualism - there are many different bodies of information in terms of which actions can be assessed, and correspondingly different values of modals for each such body. Depending on our purposes in speaking, we can talk about what an agent ought or may do relative to different bodies of information. To use the language that ethicists often use, there are values of 'ought' (and thus of 'may') that are more "objective" and those that are more "subjective". The knowledge-relative 'ought' / may' seems to occupy an intermediate value. On the more "objective" side, we sometimes want to talk about what an agent ought to do relative to all the facts - even facts outside the agent's epistemic ken. This is particularly useful in advice-giving contexts where the advice-giver is better-informed that the agent. On the more subjective side, we sometimes want to talk about what an agent ought to do relative to her beliefs - even those of her beliefs that do not amount to knowledge. This is particularly useful in cases where the facts are very contentious and so there is little conversational common ground about which of the agent's beliefs do amount to knowledge. Then we can say things like, "look, even given your own beliefs, you ought to do as I say". ${ }^{26}$

A flexible contextualist about modals does not deny that there are some values of 'ought' and 'may' which evaluate actions (and assertions, etc) in terms of the subject's knowledge. However, the contextualist picture about modals does call into question the idea that knowledge norms occupy any special, privileged role with respect to this kind of evaluation, compared with evaluation in terms of

\footnotetext{
${ }^{25}$ See chapters 28-30 of this volume for explorations of analogies between contextualism about 'knows' and about modals and other normative terms.

${ }^{26}$ These other values of 'may' are not accounted for by shifting to KNA-Doubly-Relativized. For KNA-DoublyRelativized still always ties 'may' to what the agent counts as knowing in the conversational context. These usages of 'may', by contrast, allow for speakers to include information that the agent may not count as knowing even by the contextually salient standards, or to exclude information that the agent does count as knowing by these standards.
} 
beliefs, in terms of the totality of the facts, and so on. The challenge for proponents of knowledge norms is to identify some sense in which the knowledge-relative 'may' (and 'ought') does occupy such a special, privileged role in evaluation, or in deliberation, or some sense in which all other values of 'may' are fundamentally to be explained in sense of the knowledge-relative 'may'. These are important tasks for proponents of knowledge norms who do not wish to give a semantically naïve account of modals. I will close by mentioning a few challenges that attempts to execute them may face.

As our brief survey in section 1 suggested, knowledge often plays an important role in the evaluation of assertions and actions. But the contextualist about deontic modals may have debunking explanations of some of this data that does not appeal to knowledge norms. For example, consider the intuitive clash that we saw in sentences like

(3) \#I know that the ice will hold my weight, but I shouldn't cross in case it doesn't hold my weight.

On one orthodox semantic proposal, by saying that one knows that the ice will hold one's weight, one proposes to add this piece of information to the contextually-salient body of information. ${ }^{27}$ But given that, 'shouldn't' will take a value on which the second conjunct is false. The crucial contention here is that it is the mentioning of the knowledge here, rather than one's actually having it, that guarantees that it features in the evaluation of action that follows. Indeed, we can argue that the data positively supports this explanation by contrasting (3) with:

(7) I think I know the ice will hold my weight, but I shouldn't cross in case it doesn't hold my weight. ${ }^{28}$

(7) sounds much better than (3). However, on the explanation of (3)'s badness in terms of knowledge norms, (7) ought to be bad too. For given the knowledge norm, plus suitable claims about what actions (ought to) follow from relying on the proposition that the ice will hold one's weight, the second conjunct - 'I shouldn't cross in case [the ice] doesn't hold my weight' - will be true only if one doesn't know that the ice will hold one's weight. But in general it should be bad to say 'I think X, but Y', where Y obtains only if X does not obtain. Even though 'I think' hedges the assertion of X, even such a hedged assertion should be incompatible with the outright assertion of something incompatible with $\mathrm{X}$. (Compare 'I think the hotel is on the left, but it's on the right'.)

By contrast, our rival explanation of (3)'s badness in terms of the way that claiming knowledge updates the context for the use of 'shouldn't' gives a nice explanation of why (7) is better than (3). For (7) involves no outright claim to knowledge, but rather the hedged 'I think I know'. So we get no update to the information-base for 'should' that guarantees the falsity of the second conjunct.

(7) also provides an example of a deliberative context in which one seems to exclude something that one at least may well know from one's deliberations, thus providing a counterexample

\footnotetext{
${ }^{27}$ See, e.g., Stalnaker (1999: ch. 4).

28 The example is analogous to those provided in Worsnip (2015a), where I pursue a similar line of argument against the view that all so-called "epistemic" usages of 'possible' must be understood in terms of the speaker's knowledge.
} 
to the claim that it is the knowledge-relative 'should' (and 'may') that is always at work in deliberation. The speaker in (7) seems willing, in her practical situation, only to rely on things that she is sure she knows. She might well, by the lights of what she says, in fact know that the ice will hold her weight. But in this deliberative context she is nevertheless ruling out reliance on this proposition, whether she in fact knows it or not. ${ }^{29}$

Indeed, values of 'may' that are not knowledge-relative also appear to feature in criticism in many contexts. For example, suppose that, given everything you know, it is fine to let your dog play with children. But suppose that you also unjustifiably believe that your dog is very dangerous to children. And suppose also that you still casually let your dog play with my daughter. I might well criticize your action, even though it was perfectly responsible in light of what you knew. Your having done something that by the lights of your beliefs was dangerous to my daughter itself seems criticizable. And this is not even to get started on praise and criticism of actions in terms of one's justified beliefs that fall short of knowledge because they are unluckily false, or Gettiered. ${ }^{30}$

My own view, in light of all this, is that we can evaluate actions, assertions, etc either in terms of knowledge, or in terms of justified belief, or in other terms altogether, depending on our conversational purposes. ${ }^{31}$ Now, proponents of knowledge-norms do allow that there can be different tenors of criticism that evaluate action not in terms of what the agent knew, but in terms of what (for example) the agent took herself to know. They propose somewhat breezily that these other tenors of criticism are all derivative on the central knowledge norm. ${ }^{32}$ Now, it's easy to imagine how someone might try to use the knowledge-relative 'may' to analyze the other values of 'may'. One could claim, for example, that the fact-relative 'may' is used to talk about what would be permissible if one knew all the facts, and the belief-relative 'may' is used to talk about what would be permissible if all one's beliefs amounted to knowledge.

The problem here, though, is that any such strategy seems mimicable for the claim that one of the other senses of 'may' is fundamental. If we said that the fact-relative 'may' is fundamental, we could then say that the knowledge-relative 'may' is used to talk about what would be permissible if one's knowledge exhausted the facts, and the belief-relative 'may' to talk about what would be permissible if one's beliefs exhausted the facts. Similarly, if we said that the belief-relative 'may' is fundamental, we could say that the fact-relative 'may' is used to talk about what would be permissible

${ }^{29}$ Williamson (2005: 230-5) notes, similarly, that subjects will, in high-stakes situations, only rely on propositions that they know they know. Williamson glosses a situation where the subject knows but isn't sure that she knows as one where relying on that proposition would be appropriate (in a semi-technical sense), but the subject isn't sure whether it would be appropriate. Though that maintains the letter of knowledge norms for the semi-technical notion of appropriateness, it also by the same token concedes that this notion of appropriateness is not always the one that is deliberatively relevant. ${ }^{30}$ For criticisms of knowledge norms as compared with justified-belief (or similar) norms see, e.g., Douven (2006); Lackey (2007); Stone (2007); Kvanvig (2009); Littlejohn (2009); McKinnon (2013).

31 This view should be distinguished from the superficially similar view that what is required to permissibly assert $\mathrm{p}$ (or rely on $\mathrm{p}$ in one's practical reasoning, etc) is "context-sensitive" in the sense it changes according to the subject's practical situation (so that it might sometimes be knowledge, other times justified belief, etc). (Compare Brown 2008, Gerken 2011, and Goldberg 2015). This latter view as regards permissible assertion is analogous to interest-relative invariantism about knowledge-attributions, whereas mine is genuine contextualism, where this is a semantic thesis. The litmus test as to which account is preferable is whether (e.g.) "S may rely on p" can be true in some conversational contexts and false in others, without any change in S's own situation. If it can be, we should prefer contextualist view that I favor.

32 See e.g. Williamson (2000: 243, 256-7; 2005: 227); Hawthorne \& Stanley (2008: 586); DeRose (2009: 93-4). 
if one believed all the facts, and the knowledge-relative 'may' to talk about what would be permissible if one believed only that which one knows.

So it isn't enough to simply produce a proposal for reducing all the senses of 'may' to one central sense. One has to actually show that proposal to be superior to its rivals, and to the proposal that no value of 'may' is any more fundamental than the others. It is not clear why the standard contextualist semantics for modals needs to be accompanied by any claim about fundamentality. In its more developed forms, it shows how we can get semantic predictions for 'ought' and 'may' given any potential body of information (and given other contextually variable parameters). Any claim about fundamentality can seem like a fifth wheel in such a theory; it is not required for the theory to make the right predictions.

Perhaps proponents of knowledge norms may yet be able to offer a full account that treats the knowledge-relative 'may' as fundamental and analyzes other semantic values of 'may' in terms of this central knowledge-relative notion. To do this convincingly, however, they must be more precise about what exactly the different normative notions in play are, how they fit together, and why we should take the knowledge-relative ones to be fundamental. And if potential counter-examples to knowledge norms are to be explained away in terms of "secondary" usages of normative terms, we need to be convinced that these usages really are secondary, and that it is not the knowledge-relative normative notion that turns out to be idiosyncratic or a term of art. $^{33}$

If there is one crucial lesson for the literature on knowledge norms to take heed of, then, it is the need to think sophisticatedly not just about knowledge but also about norms and normativity. For example, Williamson writes at times ${ }^{34}$ as if we need not necessarily have any genuine reason to comply with knowledge norms. ${ }^{35}$ Knowledge norms are, on this view, "merely" constitutive, much like the rules of chess. The rules of chess help to tell us what the game of chess $i s$, but it's easy to devise scenarios in which what one really ought to do is to break these rules, or even where there is really no genuine reason to comply with them. But such a view, applied to knowledge norms across the board, would clash strongly with the idea that action is genuinely criticizable, in some thick normative sense, whenever it violates the knowledge norm. These kinds of tensions, and the set of available normative and metanormative positions that arise from them, have received scant attention. The path to progress, here as in many other cases, lies in better integration of epistemology with the theory of normativity. ${ }^{36}$

\section{References}

Benton, M. (2011). 'Two More for the Knowledge Account of Assertion,' Analysis, 71/4: 684-7. Björnsson, G. \& Finlay, S. (2010). 'Metaethical Contextualism Defended,' Ethics, 121/1: 7-36.

\footnotetext{
33 Williamson (2000: 243) concedes that "false assertions are sometimes warranted in the everyday sense that they are sometimes reasonable." If knowledge-relative normative notions of warrant fails to be the "everyday sense" of such a term, we might doubt that they are really our central normative concepts.

${ }^{34}$ E.g. Williamson 2000: 240; 2005: 232.

${ }^{35} \mathrm{On}$ this view, the knowledge norm of assertion is not really normative in the strong sense of the term employed by, e.g., Kolodny (2005).

36 Thanks to Nathan Cockram and Jonathan Ichikawa for helpful comments on a previous draft.
} 
Blaauw, M. (2012). 'Reinforcing the Knowledge Account of Assertion,' Analysis, 72/1: 105-8.

Brown, J. (2005). 'Adapt or Die: The Death of Invariantism?', Philosophical Quarterly, 55/219: 263-85.

------ (2008). 'Subject-Sensitive Invariantism and the Knowledge Norm for Practical Reasoning,' Noûs, 42/2: 167-89.

------- (2012). 'Assertion and Practical Reasoning: Common or Divergent Epistemic Standards?', Philosophy and Phenomenological Research, 84/1: 124-57.

DeRose, K. (2002). 'Assertion, Knowledge, and Context,' Philosophical Review, 111/2: 167-203.

----- (2009). The Case for Contextualism. Oxford: Oxford University Press.

Dowell, J. (2013). 'Flexible Contextualism about Deontic Modals: A Puzzle about InformationSensitivity,' Inquiry, 56/2-3: 149-78.

Douven, I. (2006). 'Assertion, Knowledge, and Rational Credibility,' Philosophical Review, 115/4: 44985.

Fantl, J. \& McGrath, M. (2009). Knowledge in an Uncertain World. Oxford: Oxford University Press.

Gerken, M. (2011). 'Warrant and Action,' Synthese, 178/3: 529-47.

Goldberg, S.C. (2015). Assertion: The Philosophical Significance of a Speech Act. Oxford: Oxford University Press.

Greco, J. (2008). 'What's Wrong with Contextualism?,' Philosophical Quarterly, 58/232: 416-36.

Hawthorne, J. (2004). Knowledge and Lotteries. Oxford: Oxford University Press.

----- (2005). 'The Case for Closure,' in Steup \& Sosa (eds.), Contemporary Debates in Epistemology.

Oxford: Blackwell.

Hawthorne, J. \& Stanley, J. (2008). 'Knowledge and Action,' Journal of Philosophy, 105/10: 571-90.

Kolodny, N. (2005). 'Why Be Rational?,' Mind, 114/455: 509-63.

Kratzer, A. (1981). 'The Notional Category of Modality,' in Eikmeyer \& Rieser (eds.), Words, Worlds, and Contexts. Berlin: de Gruyter.

------ (2012). Modals and Conditionals. Oxford: Oxford University Press.

Kvanvig, J. (2009). 'Assertion, Knowledge, and Lotteries,' in Greenough \& Pritchard (eds.), Williamson on Knowledge. Oxford: Oxford University Press.

Lackey, J. (2007). 'Norms of Assertion,' Noûs, 41/4: 594-626.

Littlejohn, C. (2009). 'Must We Act Only on What We Know?,' Journal of Philosophy, 106/8: 463-73.

McKinnon, R. (2013). 'The Supportive Reasons Norm of Assertion,' American Philosophical Quarterly, 50/2: 121-35.

Nagel, J. (2008). 'Knowledge Ascriptions and the Psychological Consequences of Changing Stakes,' Australasian Journal of Philosophy, 86/2: 279-94.

Schaffer, J. (2008). 'Knowledge in the Image of Assertion,' Philosophical Issues, 18: 1-19.

Slote, M. (1979). 'Assertion and Belief,' in Dancy (ed.), Papers on Language and Logic. Keele: Keele

University Library.

Stalnaker, R. (1999). Context and Content. Oxford: Oxford University Press.

Stanley, J. (2005). Knowledge and Practical Interests. Oxford: Oxford University Press.

Stone, J. (2007). 'Contextualism and Warranted Assertion,' Pacific Philosophical Quarterly, 88/1: 92-113.

Turri, J. (2011). 'The Express Knowledge Account of Assertion,' Australasian Journal of Philosophy,

89/1: 37-45. 
Unger, P. (1975). Ignorance: A Case for Skepticism. Oxford: Oxford University Press.

Weatherson, B. (2011). 'Defending Interest-Relative Invariantism,' Logos \& Episteme, 2/4: 591-609.

Williamson, T. (2000). Knowledge and its Limits. Oxford: Oxford University Press.

------ (2005). 'Contextualism, Subject-Sensitive Invariantism, and Knowledge of Knowledge,'

Philosophical Quarterly, 55/219: 213-35.

Worsnip, A. (2015a). 'Possibly False Knowledge,' Journal of Philosophy, 112/5: 224-246.

------ (2015b). 'Two Kinds of Stakes,' Pacific Philosophical Quarterly, 96/3: 307-324. 